\title{
The Role of Phase Change Materials for Lifetime Heating of Buildings in Cold Climatic Conditions
}

\author{
Anand Kushwah \\ Mechanical Department, Madhav Institute of Technology \& Science Gwalior, India \\ Manoj Kumar Gaur, Rajindra Kumar Pandit \\ Mechanical Department, Madhav Institute of Technology \& Science Gwalior, India
}

\begin{abstract}
The study focuses on utilization of the solar insulation in buildings by means of thermal storage materials. During months of April to October, a significant part of solar gain was noticed in outer walls as well as in roof of the structure. Light weight modern construction materials have low thermal inertia so it stores less energy. The study focuses on the utilization of Phase Change Materials (PCM) for harnessing solar thermal energy for heating buildings. Various researches that show the effect of implementing PCMs in different parts of buildings like in walls, roof, windows, doors, floor etc. has been shown in the paper. The PCMs are helpful especially for those buildings which are located in cold climatic condition. Effective solutions are still required for harnessing maximum possible solar energy for heating buildings by storing heat energy by means of thermal storage materials like PCMs in hot days and to liberate it in cold night.
\end{abstract}

\author{
Article History \\ Received : 07 May 2020 \\ Received in revised form : 14 July 2020 \\ Accepted : 09 August 2020 \\ Published Online : 31 August 2020 \\ Keywords: \\ PCM; Building heating; climate \\ condition; solar in buildings; thermal \\ storage
}

\section{Corresponding Author Contact:}

anand.kushwah1989@mitsgwalior.in

DOI: $10.11113 /$ ijbes.v7.n3.600

\section{Introduction}

The entire world population and economy are rising speedily that has led to enormous growth in the world's energy demand and consumption, thus playing a massive role in causing severe ecofriendly impressions(Du K, Calautit J, Wang Z et al.2018) According to data published by Eurostat, EU member states have seen a significant increase in their final energy demand that reached approximately 1084 million tonnes of oil equivalent (MOTE) in 2015, of which 422 MTOs correspond to buildingrelated sectors Were. 39\% of total demand (Olivieri L, Tenorio JA, Revuelta D et al.2018) The Building sector, being the largest energy-consuming sector, accounts for more than $33.33 \%$ of final energy consumption on a global basis and is considered an equally important source of CO2 emissions (Devaux P, Farid MM. 2017) In addition, it was discovered that half of the energy consumption in buildings is due to heating, ventilating and air-conditioning
(HVAC) systems (Young BA, Falzone G, Wei Z.2018); Another research said that the value is $60 \%$ (Akeiber $H$, et al.2016) Integration of thermal energy storage (TES) technologies into buildings contributes to reducing peak load,Meeting the energy demand by its availability, allowing integration of renewable energy sources, and providing efficient management of thermal energy, thus improving energy efficiency in buildings. (Olivieri L, Tenorio JA, Revuelta D et al.2018)

Phase Change Materials (PCMs) works on the principle of releasing or absorbing heat by changing their phase. These can be used to store the thermal energy of sun which can be further used for heating the buildings especially during night time. This reduces the need of electricity for running heating appliances. 
Electricity is mostly generated using fossil fuels, which is not only polluting the environment but also depleting at the faster rate. The world is switching towards the renewable sources of energy for electricity generation. Among these renewable sources, solar energy is one of the best sources for fulfilling energy demand in form of heat and electric power. Solar energy has one limitation that it cannot be utilized during night time. But the solar thermal energy during day time can be stored and used during the night time. This has been tried to achieve by using thermal energy storage materials like rock bed, pebbles, sand, wax, PCMs etc. PCMs are the best alternative among these as they are capable of absorbing large amount of heat during transition of phase from liquid to solid. It releases its stored heat, during solidification process (Hu, He, Ji, \& Zhang, 2017). Temperature of PCM cannot increase as energy is stored in it as latent heat materials for heating purpose in building were proposed by Telkes and Lane in 1980 (Solar Energy, Pergamon Press 1978), (Lane, 1981) and (Zhou, Zhao, \& Tian, 2012). Since 1980s, with continuous development of building technology in China, increasing attention has been paid to wall insulation, its insulation property and construction technology(Benkel et al., 2017).

During energy crisis of late 1970's and early 1980's PCMs were widely researched for their use in solar heating systems. Role of PCMs in buildings are increasing in order to maintain the thermal comfort inside the building. PCM based building not only maintains the thermal comfort in all seasons but also reduces CO2 emission through building (Pasupathy \& Velraj, 2006a).In terms of building applications, only PCMs have a property of phase transition close to human thermal comfort, ranging from $20^{\circ} \mathrm{C}$ to $28^{\circ} \mathrm{C}$ (Pasupathy \& Velraj, 2006b).

According to chemical composition phase change materials can be classified into three categories namely organic compounds, inorganic compounds and inorganic eutectics or eutectic mixtures(Baetens, R., Jelle, B. P., \& Gustavsen, 2018). The

\section{Temperature}

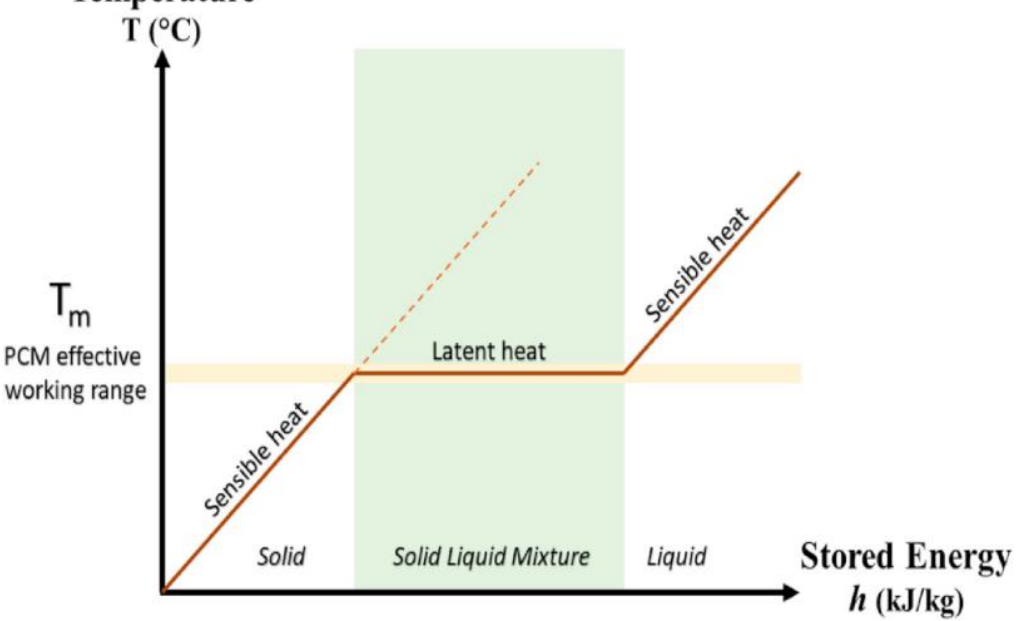

Figure 1 LES by PCM Vs. temperature change (Amaral C, Vicente R, Marques PAAP et al.2017) organic compounds can be further categorized into paraffin's and non-paraffin. The detailed classification of PCM is shown by Figure 1. Organic PCMs like wax, paraffin etc. are costlier, inflammable and produces harmful gases during combustion. While the salt hydrated inorganic phase change materials (PCMs) are inflammable, cheap and their latent heat capacity is very high. But these also have some disadvantages like high corrosiveness, instability, tendency towards incomplete re-solidification and sometimes effects of super cooling (Pasupathy and Velraj 2006a).

The paper presents the researches that show the utilization of PCM's in different parts of the buildings. In cold climate area, the heating electrical appliances become the essential part for the persons residing there. The solar energy can be used as an alternative for fulfilling this need. But it has limitation that it can be used in day time only. This limitation can be overcome by using PCM's or other thermal energy storage material that store solar thermal energy during day time and can be used during night time. The studies that had been carried out in this field are presented in the paper. This paper shows the utilization of PCMs in building and study about heating and cooling application in building. Previous study shows that in day time PCM absorb heat from solar radiation and this radiation stored in form of thermal energy and at night time PCM change our phase due to temperature difference and release the heat inside the room this cycle in done every day. This paper shows thermal performance of PCM in different climate condition and different building structure. The main motive of this paper is to present the PCM's thermal performance in the winter season. This paper concludes that the thermal comfort inside the room is dependent upon the quality of the PCM, melting point of PCM and position of PCM layer in building like roof, wall and windows. PCM integrated building is the best way to save the energy consumption and reduces carbon emission. 


\section{Background}

In 1996, by the United Nations made a protocol on Climate Change named Kyoto Protocol, many tricks and plans were made to reduce carbon emissions in this protocol and several serious steps have been taken under the Kyoto Protocol, under which all countries were instructed to reduce carbon emissions to protect the earth. The European Union fully supported the Kyoto Protocol, reducing emissions of its greenhouse gas. In 1999, 1780 million tons of energy was consumed, in which $35 \%$ of the energy was consumed in the residential and commercial area. To save energy consumption by the buildings, several measures began to be found to prevent the impact of the building on the green house. As energy accessibility and demand often does not match, thermal energy storage plays a crucial role to take advantage of solar radiation in buildings. In Europe, cold weather lasts for a longer period of time, for this, the large amount of oil and heaters are burnt for keep the building warm, due to which the energy consumption is increased and as a result the greenhouse gas emits those which contaminate our environment. Therefore, many researches will be done to keep the beings naturally warm, which can be used to heat the room both day and night using the energy of the sun. Therefore, the use of PCM is increasing rapidly, PCM changes its phase by absorbing heat energy from the sun, if it is solid then convert in liquid and if in liquid than convert in solid, At the time of day, PCM kept inside the solar energy in the form of thermal energy, then by changing its phase at night it loose the heat energy in building, which can also keep the building warm while using natural energy at night. (Baetens, R., Jelle, B. P., \& Gustavsen, 2018). Several studies have demonstrated that the use of PCMs in well-insulated buildings can reduce heating and cooling energy in residential buildings by as much as $25 \%$ and obtain similar reductions in the peak power required for air conditioning.PCM reduce the load of heater in winter season and also reduce the AC (Air conditioner) load in summer. It just doesn't only reduce energy consumption but also reduce the carbon emission from the building, because when we are using the air conditioner (AC) than it release $\mathrm{CO} 2$ gas in atmosphere. (Umair, Zhang, Iqbal, Zhang, \& Tang, 2019) There are many types of PCM available in the market such as Paraffin-Wax, Micronal DS 5000, Fatty acids, Polyethylene glycol 600 (PEG $600)$, Micronal PCM, Inorganic salt hydrate $(48 \% \mathrm{CaCl} 2+4.3 \%$ $\mathrm{NaCl}+0.4 \% \mathrm{KCl}+47.3 \% \mathrm{H} 2 \mathrm{O})$, n-Eicosane, Rubitherm GR27. The main function of PCM is that it maintains the thermal comfort of the building using latent heat, PCM is not only used as building material but it is used everywhere that comes with energy storage., As the solar distillation is done to increase water production capacity. , Even during the night, without the help of Sun, distillation would continue to be achieved. , PCM have been used in hospital for heat therapy, PCM is also used to heat tank water (Zhou et al., 2012). Based on the previous studies, it can be seen that the performance of the PCM and insulation material hinge on the weather, and the installation of these materials predominantly managed to reduce heat ventilation \& air Conditioning (HVAC's) load. As the human's comfort level is increasing, the energy consumption rate is also increasing in the building. ; Humans are ruining the environment for their comfort. PCM based building is being built to reduce energy consumption. Natural energy is used more in this type of building such as solar radiation to heat the water, and the sun's ray for providing natural light in the daytime, In order to give thermal comfort in the room; PCM is installed on roof, wall, window and floor. , Phase change material (PCM) maintains the thermal comfort inside the room by absorbing the sun's heat energy (Nazi, Wang, Chen, Zhang, \& Paul Roskilly, 2017).

\section{Concept Of PCM Heat Storage}

PCM is a material that uses latent heat during the change of phase process to control the temperature within a specific range (Jelle BP, Kalnæs SE.2017). The phase change process can change the state between liquid and gas by condensation and evaporation, known as liquid-gaseous LHTES; Or changing the phase between two solid states, known as solid-solid LHTES; Or a change in the state between solid and liquid by melting or freezing, known as solid liquid LHTES. Inferable from certain specialized impediments of the strong and fluid vaporous classifications of inactive warmth methodologies, just strong fluid PCMs are viewed as appropriate for building warming and cooling applications (Akeiber $\mathrm{H}$, et al.2016). At the point when the temperature of the PCM's encompassing ascents to such an extent that the PCM arrives at its liquefying point, the compound bonds starts its breakage with an endothermic procedure permitting the PCM to assimilate vitality, while the material melts changing its state from strong to fluid. This is the charging procedure of PCM. Next, when the temperature diminishes to arrive at the point of solidification of the PCM, securities will recover and warmth will be discharged exothermally while the PCM is recaptures its strong state. PCM along these lines is depicted to be a warm store. (Wang Q, Wu R, Wu Y et al.2018) The entire procedure of charging and releasing is went with a little volume change, under $10 \%$ of its underlying volume ( Amaral C, Vicente R, Marques PAAP et al. 2017) A delineation of the procedure is introduced in Figure 1. Truth be told, PCMs experience reasonable and inert warmth forms dependent on the quick PCM temperature contrasted with the liquefying/freezing range. At the point when the adjustment in temperature happens underneath or over the scope of stage progress, for example at a particular (fluid or strong), the reasonable vitality put away is given as (Navarro L, et al.2016)

$$
Q=m C_{p} \Delta T
$$

Where $C_{p}$ is the specific heat of phase change materials at constant pressure in $\mathrm{J} / \mathrm{KgK}$.

$m$ is the mass of phase change material in $\mathrm{Kg}$

$\Delta T$ is the Temperature Difference in Kelvin

When due to stored latent heat phase change of material occur at constant temperature, which is function of Enthalpy Change is denoted by

$$
Q=\Delta h
$$

Where $\Delta h$ is the enthalpy of phase change in $\mathrm{KJ} / \mathrm{Kg}$ Total Thermal Energy Stored in phase change material of MP tm is then evaluated as (Zeinelabdein R, Omer S, Gan G. 2017) 
$Q=\int_{t_{i}}^{t_{m}} m C_{p i} d T+m a_{m} \Delta h_{m}+\int_{t_{m}}^{t_{f}} m c_{p s} \Delta T$

$C_{p i}$ is the average specific heat at constant pressure between $t_{m}$ and $t_{i}$.

$c_{p s}$ is the average specific heat at constant pressure between $t_{f}$ and $t_{m}$.

\subsection{PCM Classification}

Phase change materials that have their charging/releasing procedure inside strong fluid progress classification are arranged into three primary classes: Organic, inorganic, and eutectic PCM (Jelle BP, Kalnæs SE.2017). These classes are partitioned further into sub-classifications. Natural PCMs covers paraffin and nonparaffin materials by which the last contains unsaturated fats, sugar alcohols, and glycols as regions. Inorganic PCMs are named salt-hydrates, liquid salts, or metals. Also, eutectic PCMs are gotten by blending at least two organics, inorganics, or natural with inorganic PCMs (Zeinelabdein R, Omer S, Gan G.2017). Figure 2 sums up the TES grouping regarding the arrangements of PCMs. Natural PCMs are materials found in nature that for the most part comprise of carbon-hydrogen chains. The upsides of natural PCMs are a few, with specific downsides that constrain their adequacy. Natural PCMs are fit for having persistent softening and freezing without stage disengagement or corruption. They are artificially steady, don't have super-cooling, are non-destructive, and recyclable. Be that as it may, they have low warm conductivity (Pandey AK, Hossain MS, V Tyagi V et al.2016) and are combustible. Inorganic PCMs are materials that offer the benefits of exceptionally high dormant warmth stockpiling limit, non-inflammability and more keen stage changes, anyway their principle downsides are in effect normally destructive, highlighted with stage isolation and super-cooling (Chandel SS, Agarwal T 2017). Eutectics are accessible as compounds of organics and additionally inorganics and generally (inorganic salt-hydrates) that highlight compatible softening/freezing with no stage isolation (Luo L, Tatsidjodoung P, Le Pierres N 2013).

PCMs with their various classes and classifications have a wide scope of liquefying temperatures whereby each has a predetermined inert warmth limit of dissolving (Figure 3). This is the primary variable to be considered while picking an appropriate PCM for a predetermined application. Truth be told, a few properties are required to guarantee most extreme warm execution. These properties are canteen physical, dynamic, concoction, practical, and ecological; and the rundown of these properties is given in Figure 4.

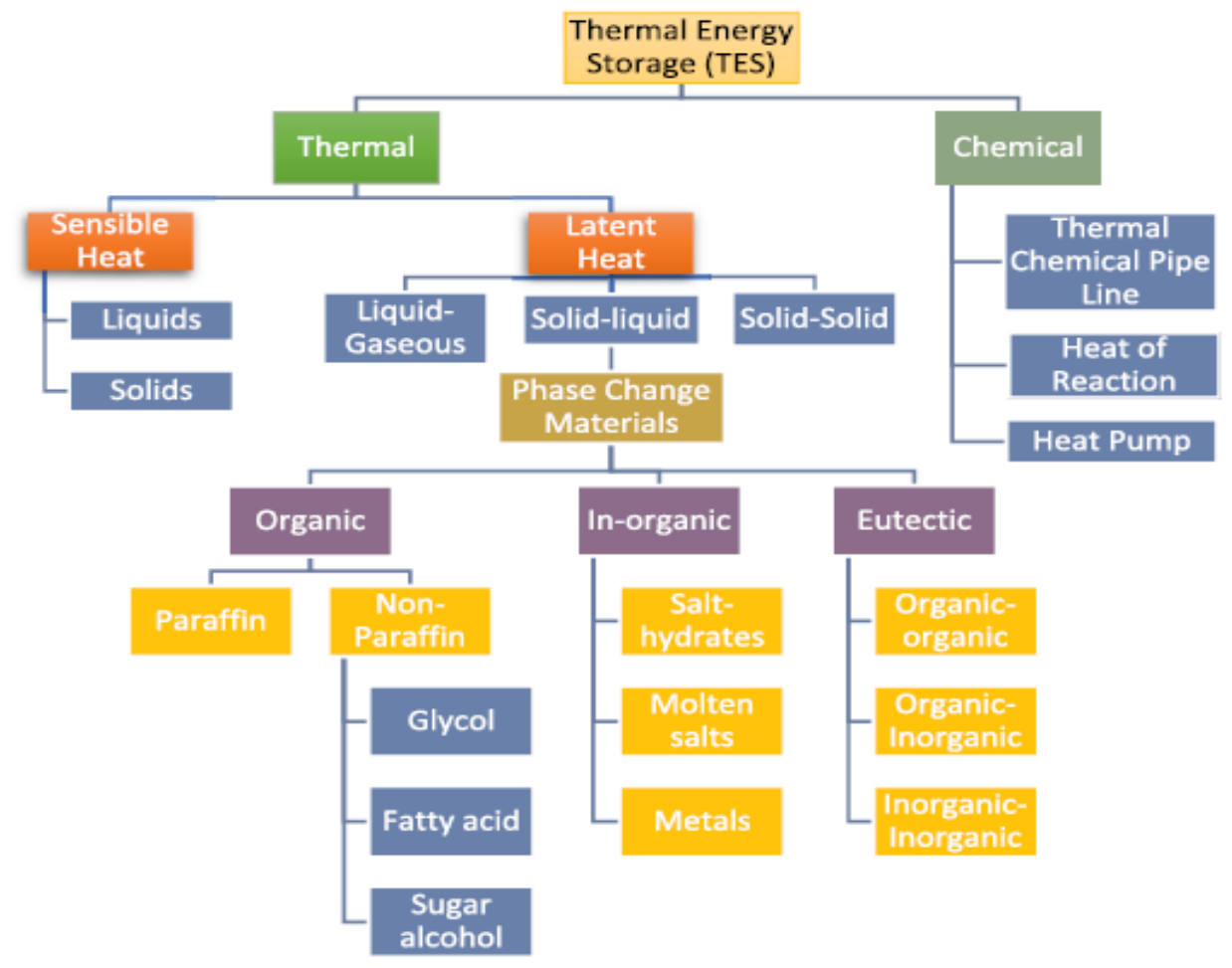

Figure 2 Classification of Phase Change Materials 


\section{Researches On Utilization Of Pcms For Building Heating Purpose}

For getting used in buildings, phase change materials must fulfil some specific thermal, physical, chemical and kinetic properties (Tyagi and Buddhi 2007).

i) Thermal properties: high latent heat of fusion, suitable phase change temperature range and good heat transfer.

ii) Physical properties: high density, small volume and suitable phase equilibrium.

iii) Chemical properties: long term chemical stability, compatibility with construction materials, no flammability and non-toxicity (De Gracia, Oró, Farid, \& Cabeza, 2011).

iv) Kinetic properties: suitable crystallization rate and no super cooling.

v)

The PCMs have been implemented at various parts of the buildings for storing and releasing the thermal energy at suitable time. The former usually uses the daily storage/release cycles, whilst the latter work on a season basis. In other words, for short time storages we can consider the heat storage during the nighttime and its release in the day time or vice versa. For annual storage, the heat is stored during the summer for its release in colder seasons or vice versa. The researches that had been taken place regarding heating of building by using PCMs are categorized into following sub-topics:

\subsection{PCM as Middle Layer}

The PCMs have been tested as the layer provided between the walls or between wall and plaster. The various PCMs have been developed and used in this way by researchers for testing their effect in term of thermal comfort of the building. In this type of wall, PCM is placed between two layers., The thermal efficiency of the building can be improved by placing PCM in the middle of material like plaster and cement, such a cold, cold and warm summer gives better performance in both the seasons. In this type of building, PCM is installed in the side wall, The advantage of putting it in the side wall is that if the sun rays fall on the wall, then the radiation is absorbed by PCM-based wall. The thermal comfort inside the building depends on the PCM's quality and location the PCM where it has been installed. There is a difference of 10 to 34 degree temperature in this type of building. This means that when the summer season arrives, the temperature of the room will be lower than the temperature of atmosphere and the temperature of the room in colder weather will be higher than the outside. The researches showing the use of PCMs in this way are listed in Table 1.

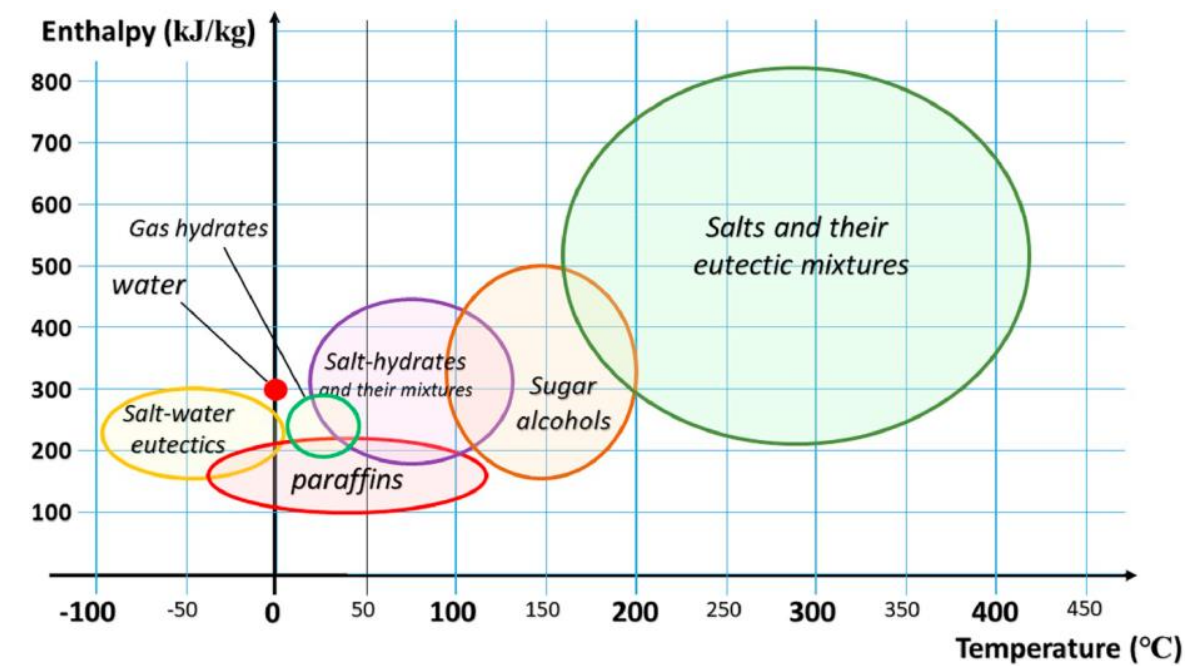

Figure 3 Melting range and melting enthalpy for different PCM types (Baetens R, Petter B, Gustavsen A.2010). 


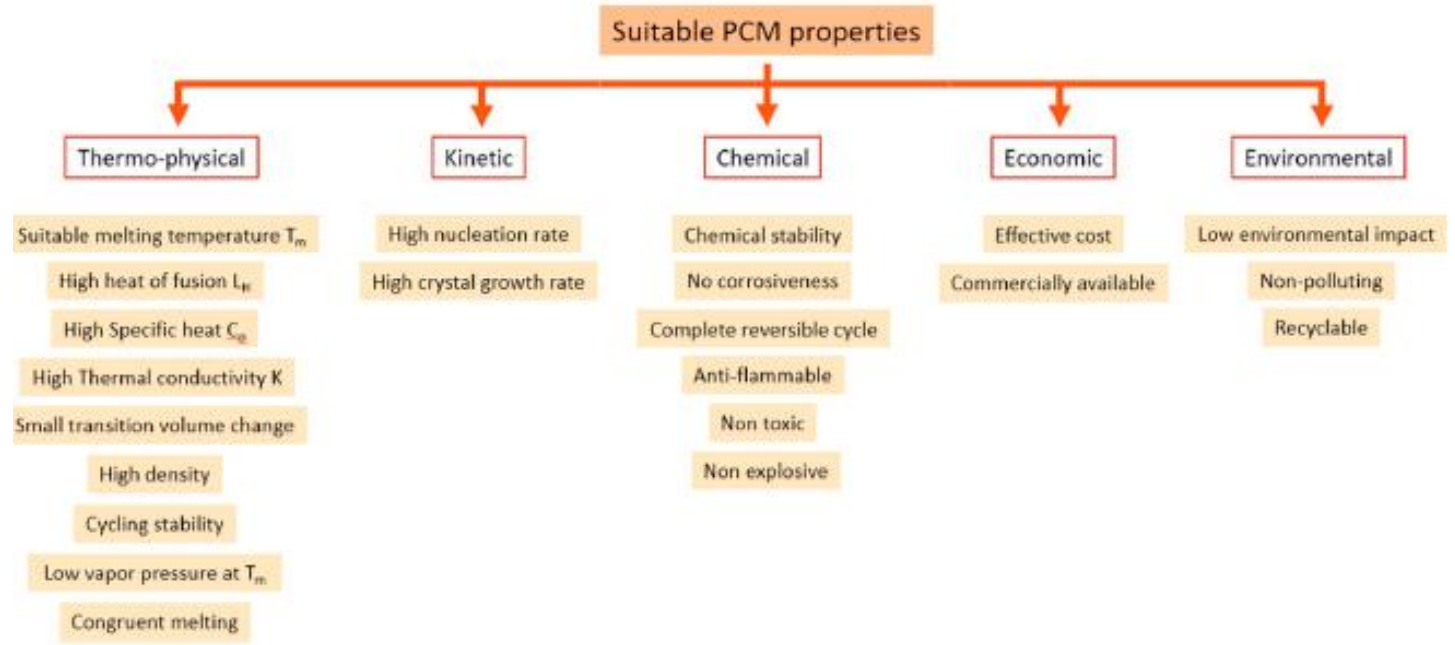

Figure 4 Thermo physical property of PCMs

Table 1 Study on the use of PCMs as middle layer

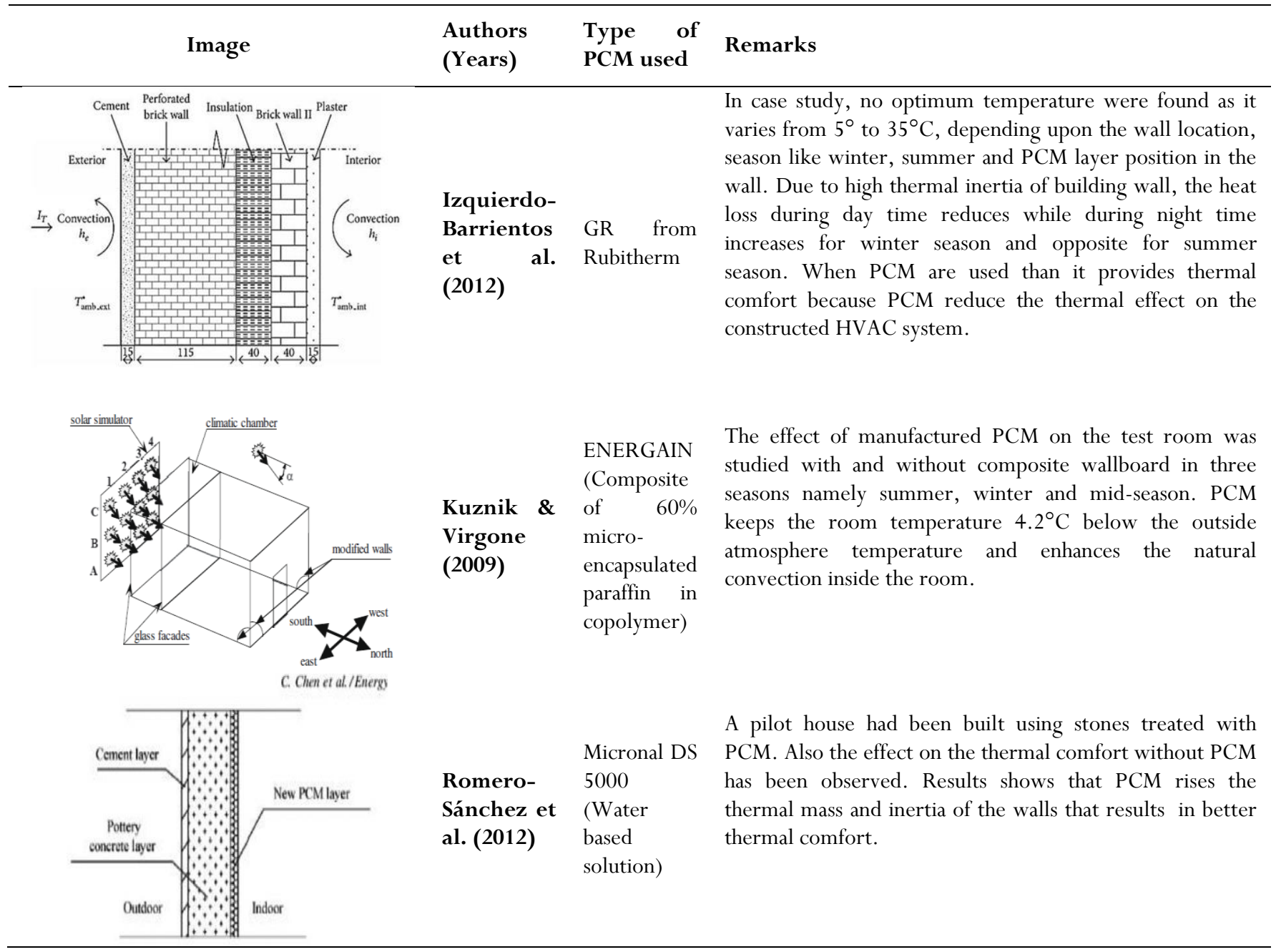




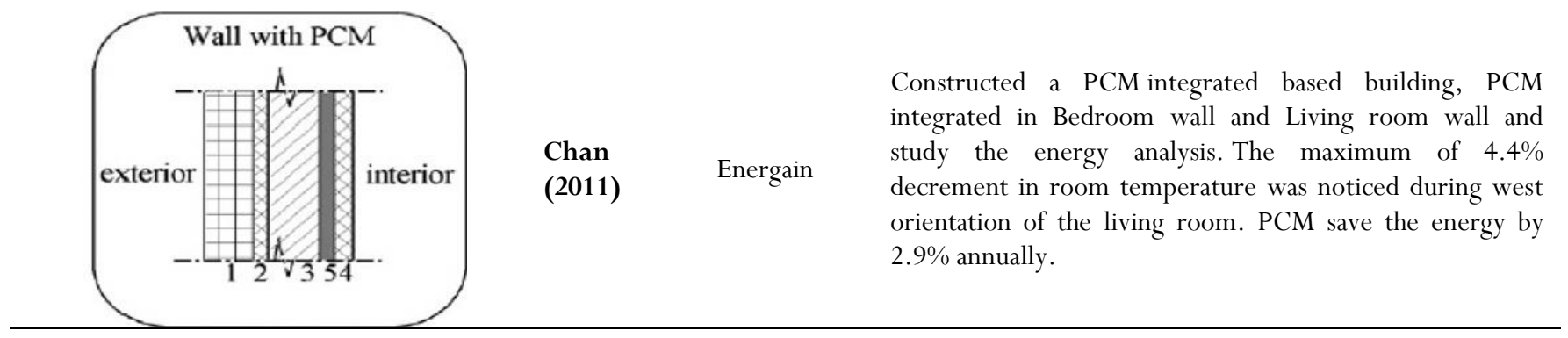

\subsection{PCM used in Internal Layer of Wall}

The PCMs have been tested as the layer integrated with internal layer of wall as it gives better thermal comfort in all seasons. In building applications, in various field PCMs can be integrated into building covering materials such as concrete, gypsum wallboard, plaster, etc., as part of building structures for light-weight or even heavy-weight buildings to increase the thermal comfort \& thermal mass. When PCM is installed in the internal layer of wall, it was found that PCM gives better performance when it is applied in the south direction wall in compare to another direction. This happens because the sun remains in the south direction for longer period, so that the radiation is obtained for longer period in that direction and the other reason is that the sun is closer to the earth in this direction. As the technology is increasing, the violence is also progressing in the field of our energy building, as it can now know about the construction and thermal performance before the building formation. Through B.L. Gowreesunker CFD analysis has been done on an Energy Build in which they have analyzed the thermal changes in the building with the help of CFD to find from which place air is coming into the building and from which place is the supply of thermal energy more. With the help of CFD, we can reduce the cost of building and also save time. , If CFD is not used, then a prototype building will have to be made, then there will be a lot of changes in prototype buildings that will waste both time and money. In this way, we can use a technology to prepare a good building ahead of time at a lower cost (Gowreesunker \& Tassou, 2013). Figure 3 shows the PCM layer is located in the side wall and few of the related researches are written in Table 2.

Table 2 Observations from various modern buildings

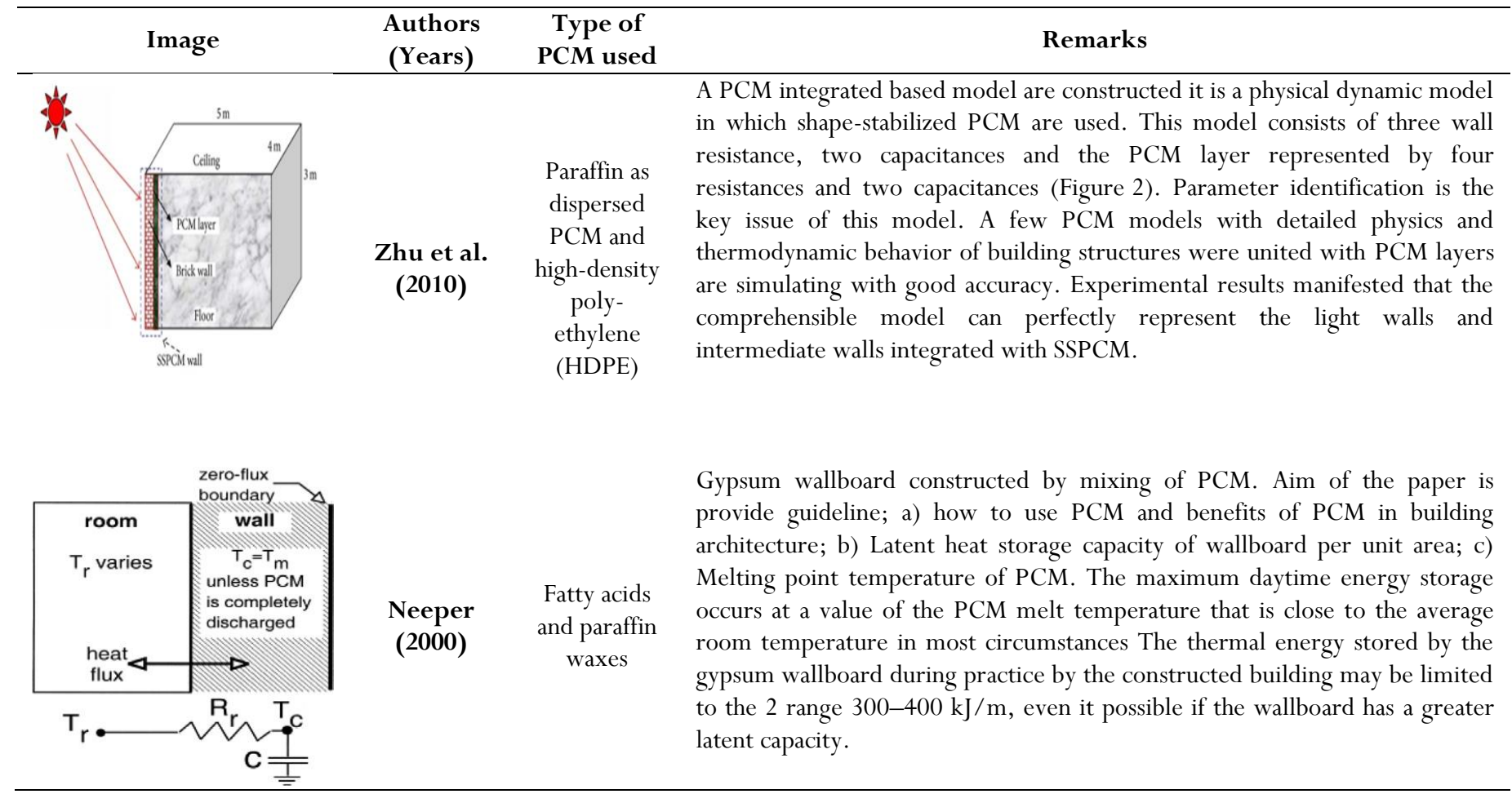




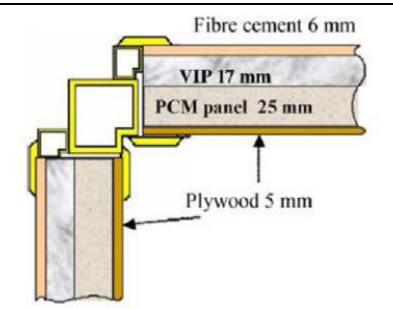

$\begin{array}{lc}\text { Ahmad et } & \begin{array}{c}\text { Polyethylene } \\ \text { glycol 600 }\end{array} \\ \text { al. (2006) } & \text { (PEG 600) }\end{array}$

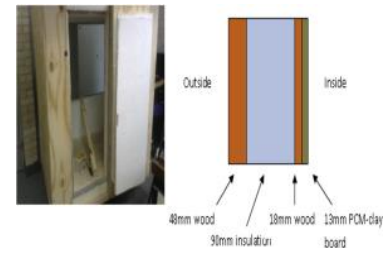

Gowreesu

nker

and Tassou

(2013)
Comparison the performance of A new structure of test-cell which is light waits wallboard with PCM integrated and test-cell without PCM. In summer season $20^{\circ} \mathrm{C}$ temperature reduces inside the structure or cell, This structure are integrated with PCM. It prevents the negative indoor temperature without PCM until the temperature of the cell is $-9^{\circ} \mathrm{C}$ and that the outside temperature is below $-6^{\circ} \mathrm{C}$ in winter. Significant heat storage and release showed by the PCM structure.

Study the effect of 1) PCM integrated wall board and it how to reduce high indoor temperature. 2) CFD analysis of air flow and temperature of indoor space. PCM integrated wall board reduce the high temperature of indoor space by $3 \mathrm{~K}$ in compare to conventional plaster boards and this construction prevents the room from overheating in month of May to July. In winter season it provides heat inside the room space. Performance of Clay wall boards dependent upon PCM quality.

\subsection{PCMs with Roof System}

It's a very effective technique to maintain the thermal performance inside the room, the PCMs have been tested as the layer provided between the roof and concrete slab or one side of the roof slab. The various PCMs have been developed and used in this way by researchers for testing their effect on the thermal comfort and energy consumption of the building. The University of South Australia has created a solar-based roof integrated solar heater and heat storage to heat the air in which corrugate iron has been used like a roof sheet, and this work as a solar collector. Planting PCM in the roof receives sufficient thermal energy, thereby increasing the energy efficiency of the building without thermal comfort lost. PCM Integrated Based Roof becomes more effective when PCM takes place in the wall apart from the roof. Building with PCM-based roofs is more beneficial for places where the winter season is much longer. The researches showing the use of PCMs in this way is listed in Table 3.

Table 3 Study on the use of PCMs in buildign roof

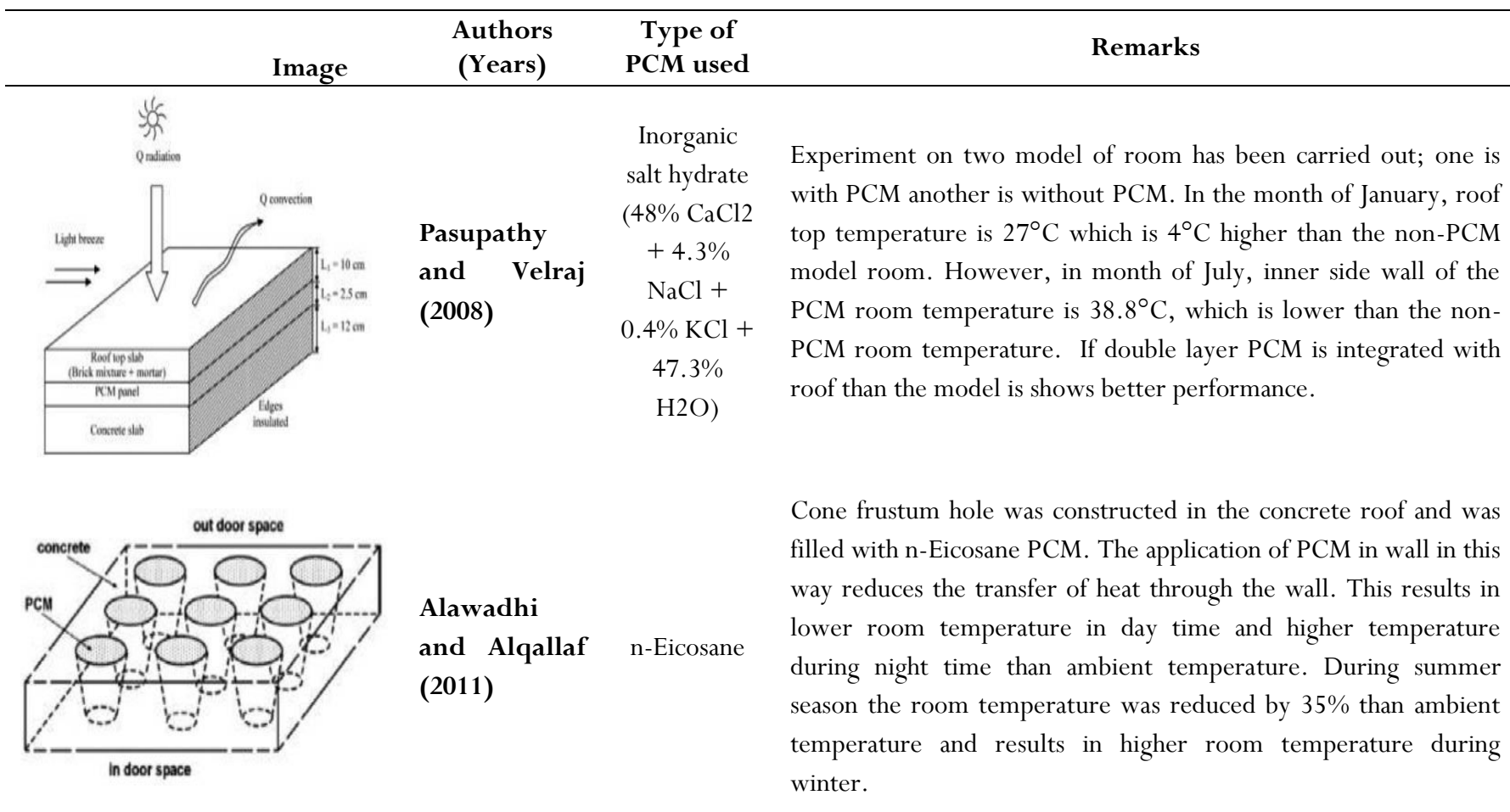




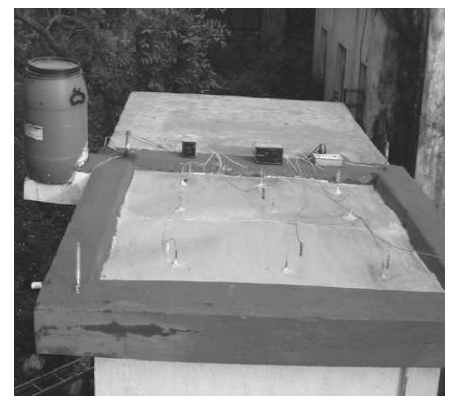

\begin{tabular}{ll} 
& \multicolumn{2}{l}{$\begin{array}{l}\text { In-organic } \\
\text { eutectic }\end{array}$} \\
Pasupathy, & PCM $\quad(48 \%$ \\
Athanasius, & $\mathrm{CaCl} 2 \quad+$ \\
and Velraj & $4.3 \% \quad \mathrm{NaCl}$ \\
(2008) & $+0.4 \% \mathrm{KCl}$ \\
& $+\quad 47.3 \%$ \\
& $\mathrm{H} 2 \mathrm{O})$
\end{tabular}

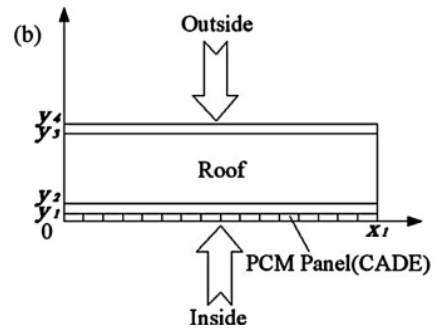

Kong et al. \& Capric (2014) acid +1dodecanol
Studied the thermal performance of in-organic eutectic PCM provided on building top roof slab for cooling and heating purpose. Effect of PCM layer thickness on building temperature was also studied and found that with increase in PCM thickness, the room temperature also increases during winter. Water flow through the pipe inside the PCM panel reduces the temperature inside the room during summer season. But it has one limitation that large amount of water is required for maintaining the thermal comfort during summer season.

Constructed a model house in which two different PCM were integrated at two different location; roof and wall. Aim of this model is increase the thermal energy inside the room, absorbed heat energy in day time by the PCM and utilizes this energy at night for thermal comfort and it saves energy consumption. Constructed model is shown better performance in the winter season

\subsection{PCM At Other Part Of Building}

For improving the thermal comfort and to reduce the energy consumption of buildings, PCMs have been tested in some other parts of building like floor and windows. Nano-PCM increases the thermal efficiency of the building and decrease energy consumption. According to the European Union (EU), buildings are responsible for $36 \%$ carbon emissions and 43\% energy consumption (Beltrán and Martínez-Gómez, 2019). PCM layers were placed on the interior surface of the wall room facing a large window of the test room and were tested in different indoor and simulated outdoor conditions (Guarino et al., 2014). PCM can be used in many places in the building and every use has the same purpose to reduce the energy consumption load in the building. Therefore, keeping the PCM in the window, roof, wall and floor, keep the thermal comfort inside the room. One such building has been where PCM has been used in the floor, in which the water is supplied from the bottom of the PCM layer with the help of pipes. It has the advantage that heat absorbed by PCM from room transfer into the cold water, thereby, maintained the thermal comfort of the room and the water also gets heated, which we can use in many other works. If this kind of setup is discussed in the cold weather, hot water is supplied in the pipeline which is heated with a solar water heater. Hot water heat is absorbed by PCM and then PCM releases this thermal energy inside the room. The temperature inside the room is also favorable in the winter season.

For reducing the carbon emission and energy consumption, PCMs are used at different locations in the building like floor and windows. PCMs in this way are listed in Table 4. 
Table 4 Studies on PCMs used at other part of building

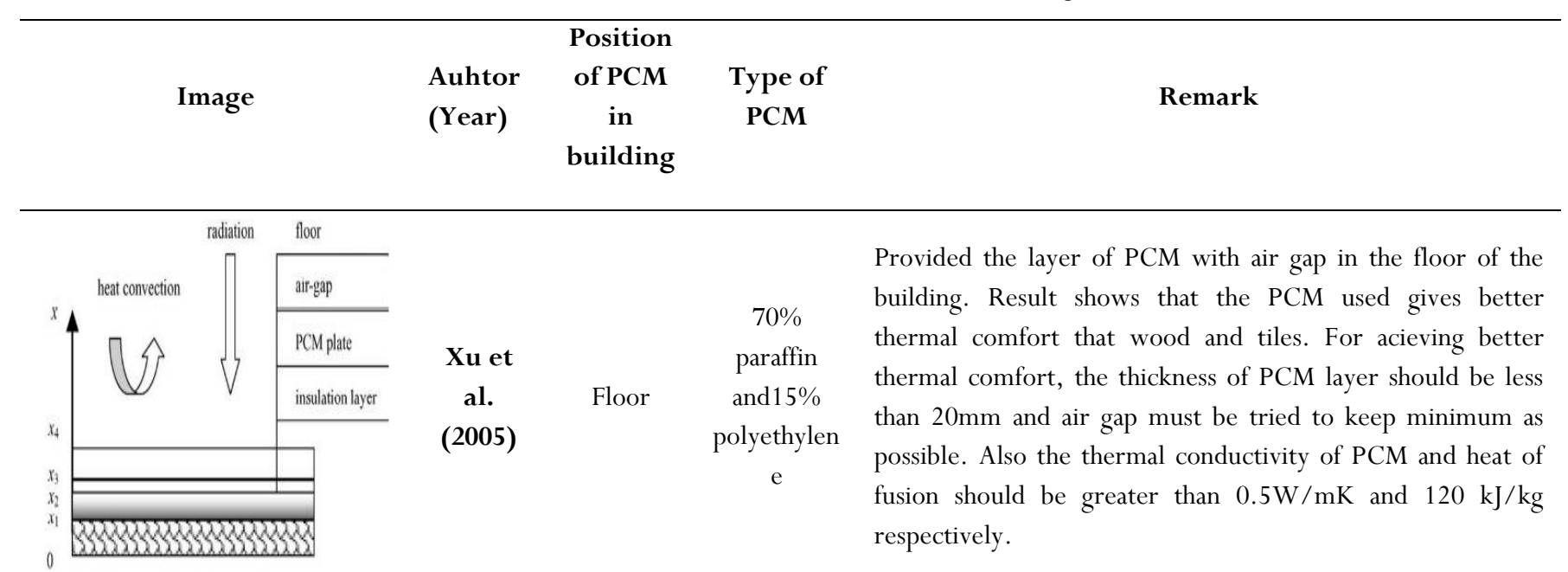

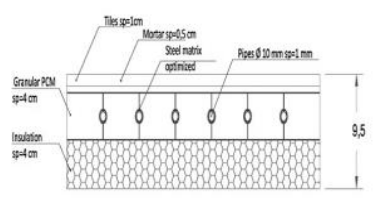

$\begin{array}{ccc}\begin{array}{c}\text { Ansuini } \\ \text { et al. }\end{array} & \text { Floor } & \text { Rubitherm } \\ \text { (2011) } & & \text { GR27 }\end{array}$

Constructed the prototype with radiant floor integrated with PCM and water pipe. This prototype save $25 \%$ of water (2011) which is wasted in cooling the room during summer. In winter also it did not affect the heating behaviour of room thus maintaing the thermal comfort during all seasons.

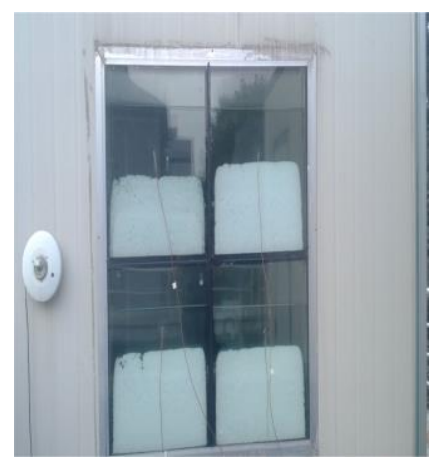

$\begin{array}{ccc}\text { Li et al. } & \text { Paraffin } \\ \text { (2016) } & \text { Window } & \text { MG29 }\end{array}$

Tested the effect of PCM in three conditions namely tripel pane window with PCM, double pane window with PCM and tripal pane window without PCM. Results shows that triple pane window with PCM shows better performance in all the seasons. During summer season it allows $16.6 \%$ and $28 \%$ less heat as compared to double pane with PCM and triple pane without PCM windows respectively. During rainy season also, it maintains the inside temperature $0.74^{\circ} \mathrm{C}$ and $1.65^{\circ} \mathrm{C}$ less than double pane with PCM and triple pane without PCM windows respectively.

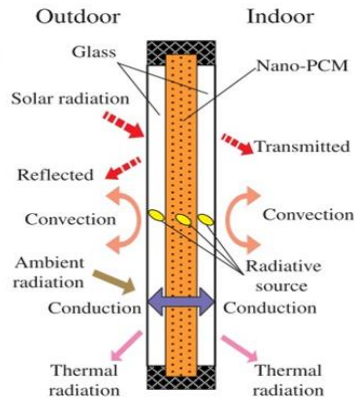

\section{Li et}

al. Window

(2018)
The PCM was mixed with nano particles and applied over the window panes. The nano particles increases the thermal capacity of the PCM and improves the performance. Result shows that the inner temperature of nano-PCM glazed window increases with increase in nano particle size and its Paraffin concentration. This model reduces the energy consumption wax by $1.5 \%, 2 \%$ and $4 \%$ during summer, autumn and winter season respectively. 1)Temperature of inner side glass surface is depending upon concentration and nanoparticle size, when the concentration increase $1 \%$ and diameter of Nanoparticles of $100 \mathrm{~nm}$ than inner glass surface temperature is increased. 


\section{Researches On Utilization Of Pcms For Building Cooling Purpose}

PCMs applications are appropriate for both new structures and the retrofitting of existing ones (Jelle BP, Kalnæs SE.2017). The method of consolidation, dissolving range, and wanted utility describe the working method of the utilized PCM-TES framework. PCM-TES can be utilized for warming, cooling, or for both warming and cooling, which are alluded to as cross breed frameworks. The basics behind cooling applications utilizing PCM states that: when the considered warm zone is exposed to an expansion in encompassing temperature that may pass the solace run gave by the American Society of Heating, Refrigeration and Air-Conditioning Engineers, during hot condition (24 degree Celsius for a stickiness not exactly or equivalent half) (McQuiston F, Parker J, Spitler J.2005), at that point PCMs play their job in putting away the abundance heat through their steady temperature retention capacities. Figure 6 outline the stage change marvels during cooling use of the PCM.
The softening scope of PCM is then reliant on the arrangement of the PCM in the zone, kind of utilization using the PCM, and wanted cooling set point. Every mode is partitioned into inactive and dynamic classifications. (Heier et al.2015) states that the contrast among dynamic and latent frameworks is the main impetus of charging and releasing the capacity where dynamic stockpiling uses siphons or fans while detached capacity relies just upon the temperature distinction between the capacity and environmental factors. As indicated by (Suayfane et al.2016), the cooling request in the structure area has expanded quickly attributable to: (1) high necessity for tenants' solace, (2) ascent of structures inward warmth increases, (3) effect of urban warmth island experienced in stuffed urban communities, and (4) decreased expense of cooling hardware. Coordinating PCM into structures can diminish the cooling cost and improve the warm solace during hot seasons.

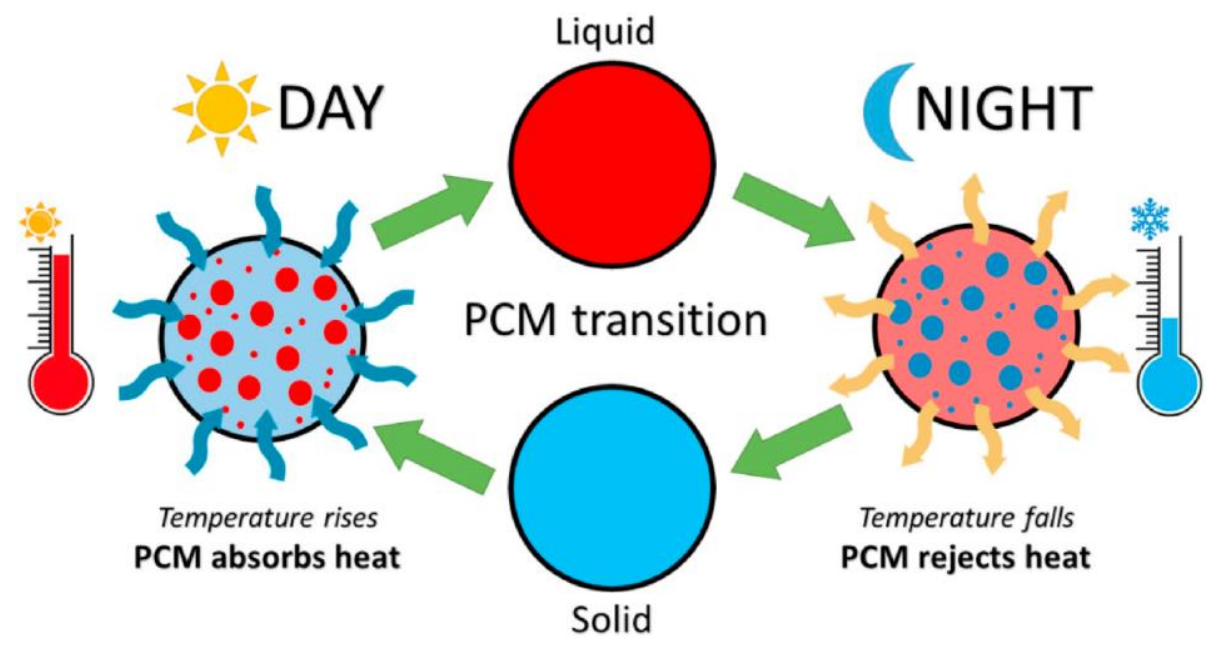

Figure 6 Phase change of PCM throughout warm climates 
Table 5 Previous Study on PCM cooling applications for buildings.

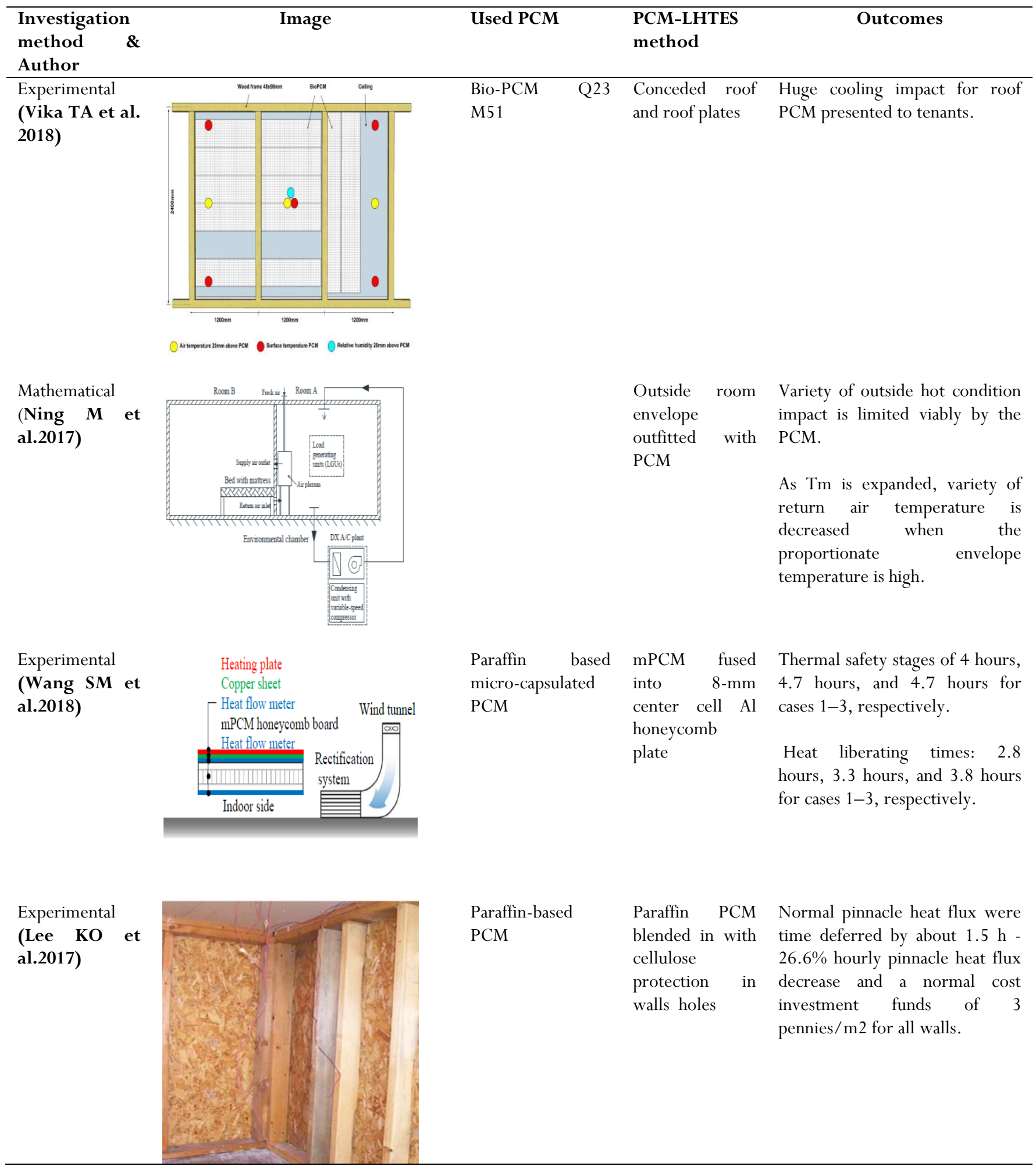


Experimental and Numerical (Stritih U et al. 2018)
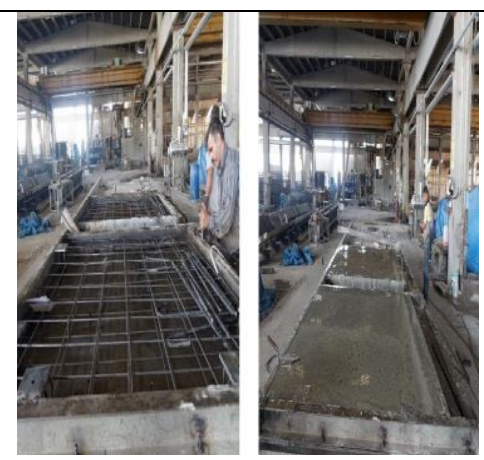

Experimental and Numerical (Yao c et al. 2017)

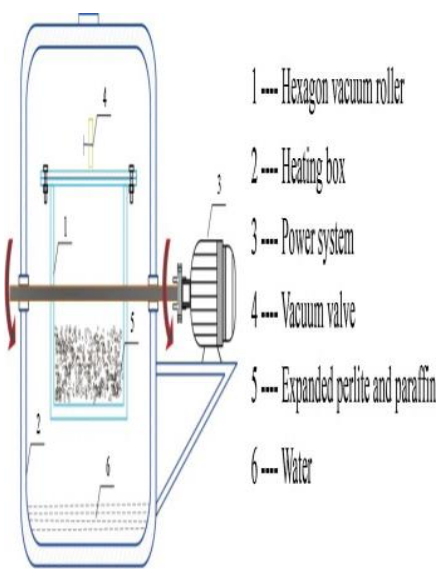

Experimental and Numerical (Biswas K eat al.2014)
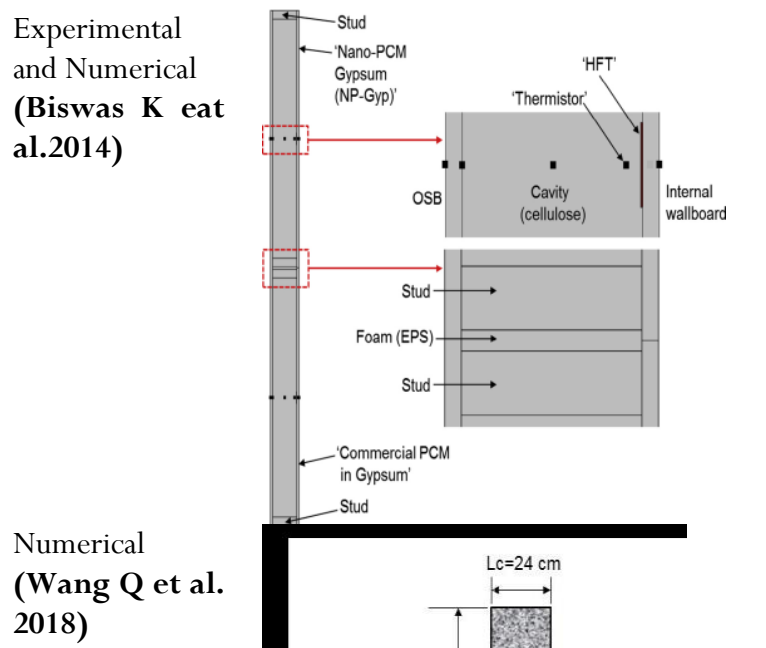

Paraffin, heptadecane (C17H36)

Paraffin/ extended perlite SSPCM

\section{Wallboard}

gypsum

\section{RUBITHERM} RT-line PCM
Inside surface of the test lodge is colder by 5 degree celcius than the reference board.
(PCMW) joined to the inner surface of the dividers and ceiling of tried model.

PCMW improves warm solace, smoothens indoor temperature vacillation, and increment the structure vitality effectiveness.

Numerical model is approved with a certainty level $>95 \%$.

Numerically, for $4000 \mathrm{~m} 2$ office, cooling load decrease of $22.16 \%, 5.84$ years restitution period, and a life expectancy $>20$ years is accomplished.

Optimum PCMW: have a stage change temperature scope of 25 26 degree Celsius and thickness $10 \mathrm{~mm}$.

Wallboard - For a cooling set purpose of 22 degree Celsius, the most noteworthy yearly divider heat gain decrease was accomplished.

No decrease in heat gains for the instances of 22 and 23.3 degree Celsius set focuses.

Potential of electrical utilization decrease is shown by the NanoPCM wallboard

PCM layer joined into solid wall,
Heat transfer rate and normal inward surface temperature are decreased by utilizing PCM.

The ideal PCM type, thickness, and position are RT42 with 20 mm thickness, put outside.

Heat transfer decrease of $34.9 \%$ was accomplished 


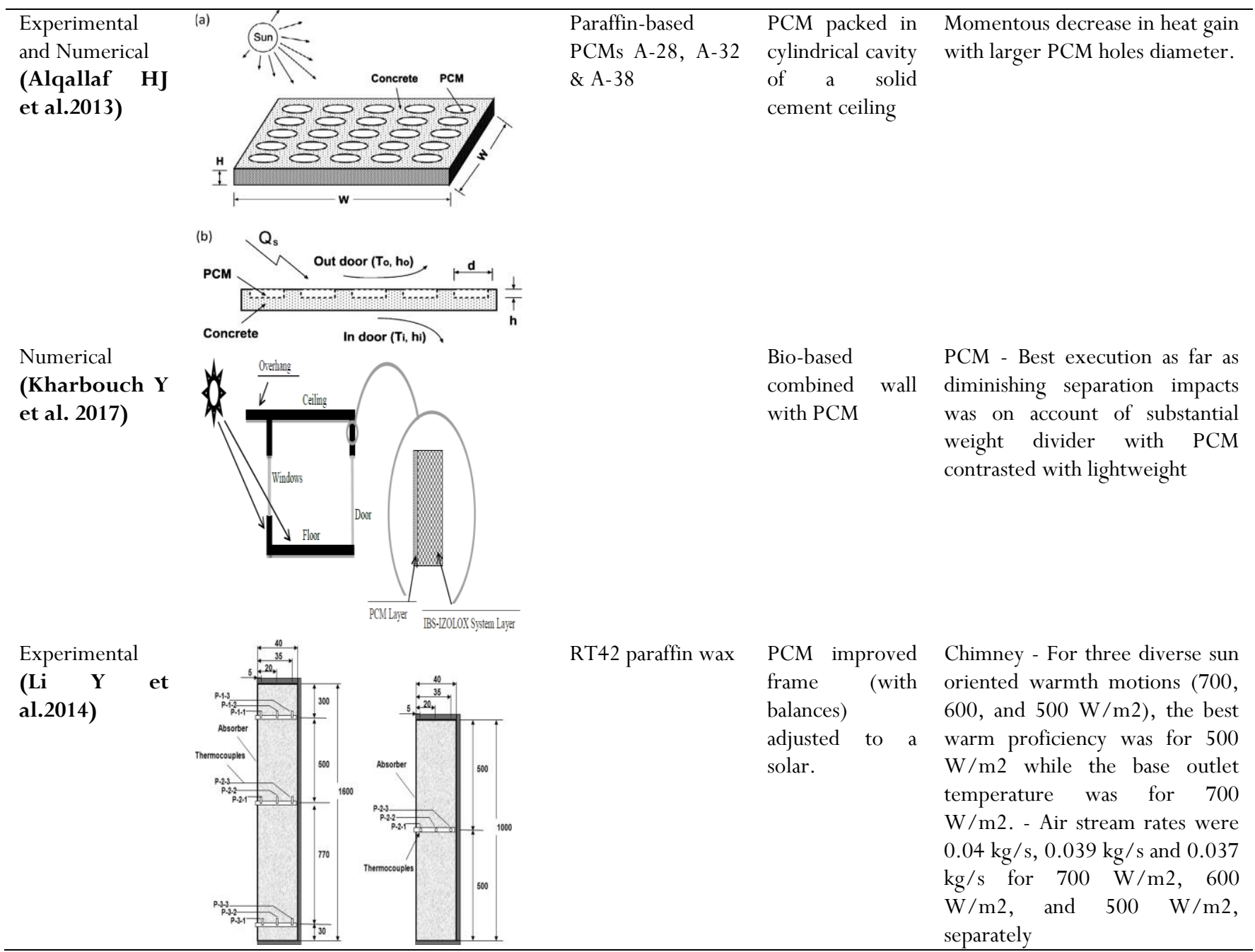

\section{Conclusion}

The present effort represented a review on latest research work in the scientific community concerning the usage of phase change materials as latent heat thermal energy storage policies uses to buildings: commercial as well as residential. Two most application characteristics were presented: heating applications in buildings, cooling applications in buildings. The current reviewed articles were presented and their thermal performance analyses were included. Phase change materials are coming up as the best alternatives for utilization of solar thermal energy. Especially these are helpful during winter season or buildings in cold climatic zone for maintaining the thermal comfort inside the buildings. Thermal comfort in buildings integrated with PCMs depends on the various factors like quality, quantity, melting point and location of PCM. The PCM not only keeps the inside temperature of the building higher than ambient during winters but also able to do the just opposite during summer. The one reason that is responsible for maintaining the thermal comfort in all the seasons is the higher thermal inertia.

The PCM layer where ever applied in building, increases the thermal inertia due to which the heat transfer from outside to inside the building reduces. Secondly, the PCM layer inside the structure absorbs the heat by changing its phase from solid to liquid during day time and release it during night time by again coming back to its original phase. The effect of PCM had been tested by placing them in windows, walls, roof and floor. When PCM is put in two different places inside the room, then it saves $4 \%$ of energy consumption. When the PCM is attached to the roof, the temperature of the room is increased by 4 to $5 \%$ compared to another applied position of PCM. Nano-PCM based glazed window shows better performance in winter season, Temperature of the inner side glass surface is depending upon concentration and nano-particle size. It reduces the energy consumption by $1.5 \%$ in summer, $2.0 \%$ in autumn $\& 4.0 \%$ in winter season.

PCM do help as thermal buffers that permits residential thermal comfort in winter cold climates through peak instable and temperature fluctuate reduction. 


\section{References}

Ahmad, M., Bontemps, A., Sallée, H., \& Quenard, D. (2006). Thermal testing and numerical simulation of a prototype cell using light wallboards coupling vacuum isolation panels and phase change material. Energy and Buildings, 38(6): 673-681. https://doi.org/10.1016/j.enbuild.2005.11.002

Akeiber H, et al. (2016). A review on phase change material (PCM) for sustainable passive cooling in building envelopes. Renew Sustain Energy Rev. 60:1470-97.

Alqallaf HJ, Alawadhi EM. (2013) Concrete roof with cylindrical holes containing PCM to reduce the heat gain. Energy Build. 61: 73-80.

Amaral C, Vicente R, Marques PAAP, Barros-timmons A (2017). Phase change materials and carbon nanostructures for thermal energy storage: a literature review. Renew Sustain Energy Rev. 79(January): 1212-28.

Alawadhi, E. M., \& Alqallaf, H. J. (2011). Building roof with conical holes containing PCM to reduce the cooling load : Numerical study. Energy Conversion and Management, 52(8-9): 2958-2964. https://doi.org/10.1016/j.enconman.2011.04.004

Ansuini, R., Larghetti, R., Giretti, A., \& Lemma, M. (2011). Radiant floors integrated with PCM for indoor temperature control. Energy and Buildings, 43(11): 3019-3026. https://doi.org/10.1016/j.enbuild.2011.07.018

Baetens, R., Jelle, B. P., \& Gustavsen, A. (2018). Phase Change Materials for Building Applications. Buildings 2018, 42: 1361-1368. https://doi.org/10.3390/buildings8050063

Baetens R, Petter B, Gustavsen A. (2010). Phase change materials for building applications: a state-of-the-art review. 42(2012): 1361-8.

Beltrán, R. D., \& Martínez-Gómez, J. (2019). Analysis of phase change materials (PCM) for building wallboards based on the effect of environment. Journal of Building Engineering, 24: https://doi.org/10.1016/j.jobe.2019.02.018

Benkel, T., Richel, N., Badel, A., Chaud, X., Lecrevisse, T., Borgnolutti, F., ... Tixador, P. (2017). Preliminary Tests and Margin Estimate for a REBCO Insulated $10 \mathrm{~T}$ Insert under High Magnetic Field. IEEE Transactions on Applied Superconductivity, 27(4): 689-701 https://doi.org/10.1109/TASC.2017.2654418

Biswas K, Lu J, Soroushian P, Shrestha S.(2014) Combined experimental and numerical evaluation of a prototype nano-PCM enhanced wallboard q. Applied Energy. 131: 517-29

Chandel SS, Agarwal T.(2017) Review of current state of research on energy storage, toxicity, health hazards and commercialization of phase changing materials. Renew Sustain Energy Rev. 67:581-96.

De Gracia, A., Oró, E., Farid, M. M., \& Cabeza, L. F. (2011). Thermal analysis of including phase change material in a domestic hot water cylinder. Applied Thermal Engineering, 31(17-18): 3938-3945. https://doi.org/10.1016/j.applthermaleng.2011.07.043

Devaux P, Farid MM. (2017). Benefits of PCM underfloor heating with PCM wallboards for space heating in winter. Applied Energy, 191:593602.
Du K, Calautit J, Wang Z, Wu Y, Liu H. (2018) A review of the applications of phase change materials in cooling, heating and power generation in different temperature ranges. Applied Energy. 220(March):242-73

Gowreesunker, B. L., \& Tassou, S. A. (2013). Effectiveness of CFD simulation for the performance prediction of phase change building boards in the thermal environment control of indoor spaces. Building and Environment, 59: 612-625. https://doi.org/10.1016/j.buildenv.2012.10.004

Gowreesunker, B. L., \& Tassou, S. A. (2013). Effectiveness of CFD simulation for the performance prediction of phase change building boards in the thermal environment control of indoor spaces. Building and Environment, 59: 612-625. https://doi.org/10.1016/j.buildenv.2012.10.004

Guarino, F., Dermardiros, V., Chen, Y., Rao, J., Athienitis, A., Cellura, M., \& Mistretta, M. (2014). PCM thermal energy storage in buildings: Experimental study and applications. Energy Procedia, 70: 219-228. https://doi.org/10.1016/j.egypro.2015.02.118

Hu, Z., He, W., Ji, J., \& Zhang, S. (2017). A review on the application of Trombe wall system in buildings. Renewable and Sustainable Energy Reviews, 70(August 2015): 976-987. https: / / doi.org/10.1016/j.rser.2016.12.003

Jelle BP, Kalnæs SE. (2017) Phase change materials for application in energy-efficient buildings. Elsevier Ltd

Kong, X., Lu, S., Li, Y., Huang, J., \& Liu, S. (2014). Numerical study on the thermal performance of building wall and roof incorporating phase change material panel for passive cooling application. Energy and Buildings, 81: 404-415. https://doi.org/10.1016/j.enbuild.2014.06.044

Kuznik, F., \& Virgone, J. (2009). Experimental assessment of a phase change material for wall building use. Applied Energy, 86(10): 2038 2046. https://doi.org/10.1016/j.apenergy.2009.01.004

Lane, G. A. (1981). Adding strontium chloride or calcium hydroxide to calcium chloride hexahydrate heat storage material. Solar Energy, 27(1): 73-75. https://doi.org/10.1016/0038-092X(81)90023-2

Lee KO, Medina MA, Sun X, Jin X (2018). Thermal performance of phase change materials (PCM)-enhanced cellulose insulation in passive solar residential building walls. Sol Energy.; 163(November 2017):11321.Air - experimental and numerical investigations. Sustain. Cities Soc. $2017 ; 37$

Li, D., Wu, Y., Liu, C., Zhang, G., \& Arıc1, M. (2018). Energy investigation of glazed windows containing Nano-PCM in different seasons. Energy Conversion and Management, 172(April): 119-128. https://doi.org/10.1016/j.enconman.2018.07.015

Li, S., Sun, G., Zou, K., \& Zhang, X. (2016). Experimental research on the dynamic thermal performance of a novel triple-pane building window filled with PCM. Sustainable Cities and Society, 27: 15-22. https://doi.org/10.1016/j.scs.2016.08.014

Luo L, Tatsidjodoung P, Le Pierres N. (2013) A review of potential materials for thermal energy storage in building applications. Renew Sustain Energy Rev. 18: 327-49. 
McQuiston F, Parker J, Spitler J. (2005) Heating, ventilating and air conditioning analysis and design. Sixth ed. John Wiley \& Sons, Inc.; 2005.

Navarro L, et al. (2016) Thermal energy storage in building integrated thermal systems: a review. Part 1. Active storage systems. 88 .

Nazi, W. I. W. M., Wang, Y., Chen, H., Zhang, X., \& Paul Roskilly, A. (2017). Passive Cooling Using Phase Change Material and Insulation for High-rise Office Building in Tropical Climate. Energy Procedia, 142: 2295-2302. https://doi.org/10.1016/j.egypro.2017.12.632

Neeper, D. A. (2000). Thermal dynamics of wallboard with latent heat storage. Solar Energy, 68(5): $393-403$. https://doi.org/10.1016/S0038-092X(00)00012-8

Ning M, Jingyu H, Dongmei P, Shengchun L, Mengjie S.(2017) Investigations on thermal environment in residential buildings with PCM embedded in external wall. Energy Procedia. 142:1888-95.

Olivieri L, Tenorio JA, Revuelta D, Navarro L, Cabeza LF. (2018). Developing a PCM-enhanced mortar for thermally active precast walls. Construction Build Mater, 181: 638-49.

Pandey AK, Hossain MS, V Tyagi V, Abd N, Selvaraj JAL, Sari A. (2016) Novel approaches and recent developments on potential applications of phase change materials in solar energy. Renew Sustain Energy Rev. 82: 281-323.

Pasupathy, A., Athanasius, L., \& Velraj, R. (2008). Experimental investigation and numerical simulation analysis on the thermal performance of a building roof incorporating phase change material (PCM) for thermal management. Applied Thermal Engineering, 28: 556 565. https://doi.org/10.1016/j.applthermaleng.2007.04.016

Pasupathy, A., \& Velraj, R. (2006a). Phase change material based thermal storage for energy conservation in building architecture. International Energy Journal, 7(2), 147-159.

Pasupathy, A., \& Velraj, R. (2006b). Phase change material based thermal storage for energy conservation in building architecture. International Energy Journal, 7(2):147-159.

Pasupathy, A., \& Velraj, R. (2008). Effect of double layer phase change material in building roof for year round thermal management. Energy and $\quad$ Building 40: 193-203. https://doi.org/10.1016/j.enbuild.2007.02.016
Umair, M. M., Zhang, Y., Iqbal, K., Zhang, S., \& Tang, B. (2019). Novel strategies and supporting materials applied to shape-stabilize organic phase change materials for thermal energy storage-A review. Applied Energy, 235(October 2018): 846-873. https://doi.org/10.1016/j.apenergy.2018.11.017

Vik TA, Madessa HB, Aslaksrud P, Folkedal E, vrevik OS.(2017). Thermal performance of an office cubicle integrated with a bio-based PCM: experimental analyses. Energy Procedia, 111 (1876):609-18.

Wang SM, Matiasovský P, Mihalka P, Lai CM. (2018).Experimental investigation of the daily thermal performance of a $\mathrm{mPCM}$ honeycomb wallboard. Energy Build. 159:419-25.

Wang Q, Wu R, Wu Y, Zhao CY (2018) Parametric analysis of using PCM walls for heating loads reduction. Energy Build. 172: 328-36.

Xu, X., Zhang, Y., Lin, K., Di, H., \& Yang, R. (2005). Modeling and simulation on the thermal performance of shape-stabilized phase change material floor used in passive solar buildings. Energy and Buildings, 37(10): 1084-1091. https://doi.org/10.1016/j.enbuild.2004.12.016

Yao C, Kong X, Li Y, Du Y, Qi C. (2017) Numerical and experimental research of cold storage for a novel expanded perlite-based shape stabilized phase change material wallboard used in building. Energy Convers Management. 155(June 2017):20-31.

Young BA, Falzone G, Wei Z, Sant G, (2018) Pilon L. Reduced-scale experiments to evaluate performance of composite building envelopes containing phase change materials. Construction Build Mater. 162:584 95.

Zeinelabdein R, Omer S, Gan G. (2018). Critical review of latent heat storage systems for free cooling in buildings. Renew Sustain Energy Rev 82: 2843-68.

Zhou, D., Zhao, C. Y., \& Tian, Y. (2012). Review on thermal energy storage with phase change materials (PCMs) in building applications. Applied Energy, 92: 593-605. https://doi.org/10.1016/j.apenergy.2011.08.025

Zhu, N., Wang, S., Xu, X., \& Ma, Z. (2010). A simplified dynamic model of building structures integrated with shaped-stabilized phase change materials. International Journal of Thermal Sciences, 49(9): 1722 1731. https://doi.org/10.1016/j.ijthermalsci.2010.03.020 